\title{
GAMBARAN DAN PENGENDALIAN IKLIM KERJA DENGAN KELUHAN KESEHATAN PADA PEKERJA
}

\author{
Merry Sunaryo, Muslikha Nourma Rhomadhoni \\ Program Studi D-VI Kesehatan dan Keselamatan Kerja, Fakultas Kesehatan \\ Universitas Nahdlatul Ulama Surabaya \\ Email: merry@unusa.ac.id
}

\begin{abstract}
In a working climate with hot temperatures, it begins with the emergence of energy that comes from the heat that enters the environment or workplace and then becomes hot pressure, it becomes an additional workload for workers. Such conditions affect the health and energy/stamina of workers when associated with the heavy workload done. Conditions Working climate with hot temperatures can aggravate the physical and mental health conditions of workers. The impact that often occurs on workers due to hot work climates, namely dehydration and other health complaints such as heat rash. used as the basis for taking control measures to prevent occupational diseases in the industry. Measurement of the working climate carried out in the work section in the candle making industry. it is known to have results that most of them have ISBB values>30oC. Based on the observations that have been made on the workload of workers, namely workload with a moderate level with work time $75 \%$ to $100 \%$ with $25 \%$ rest time. Based on the 10 point average results from the two work sections in the industry, most of the ISBB values measured are greater than the NAV value that has been determined, with a NAV value of $280 \mathrm{C}$. In health complaints that are often felt by workers, namely, dehydration is felt by many workers because workers rarely have sufficient fluid or water intake. Likewise, with heat rash complaints, this complaint is felt by workers who rarely maintain personal hygiene. Therefore, it is necessary to control the working climate both in the environment and in the workers. The controls are such as training (education/training), controlling heat stress through the application of hygiene.
\end{abstract}

Keywords: Work Climate, Ceramic Industry, TLV

\begin{abstract}
ABSTRAK
Pada Iklim kerja dengan suhu panas berawal dari timbulnya energi yang bersumber dari panas yang masuk ke lingkungan atau tempat kerja kemudian jadi tekanan yang panas, hal tersebut menjadi beban kerja tambahan untuk pekerja. Kondisi seperti itu memengaruhi kesehatan dan energi/ stamina pekerja jika dihubungkan dengan beban kerja berat yang dikerjakan. Kondisi Iklim kerja dengan suhu panas dapat memperberat kondisi kesehatan fisik dan mental pekerja. Dampak yang sering terjadi pada pekerja akibat iklim kerja panas yaitu dehidrasi dan keluhan kesehatan lain seperti heat rash. Tujuan dari penelitian ini adalah untuk mengetahui gambaran dan pengendalian iklim kerja dengan keluhan kesehatan pada pekerja, hasil tersebut nantinya akan dibandingkan dengan nilai ambang batas sehingga dapat dijadikan dasar dalam melakukan tindakan pengendalian dalam upaya pencegahan penyakit akibat kerja pada industri. Pengukuran Iklim kerja yang dilakukan pada bagian kerja di indutri pembuatan lilin, diketahui memiliki hasil yaitu sebagian besar memiliki nilai ISBB $>30^{\circ} \mathrm{C}$. Berdasarkan pengamatan yang telah dilakukan beban kerja pada pekerja yaitu beban kerja dengan
\end{abstract}


tingkatan sedang dengan waktu kerja $75 \%$ hingga 100\% dengan 25\% waktu beristirahat. Berdasarkan hasil rata-rata 10 titik dari ke dua bagian kerja di industri tersebut, sebagian besar nilai ISBB hasil pengukuran lebih besar dari nilai NAB yang telah ditetapkan, dengan nilai NAB $28^{\circ} \mathrm{C}$. Pada keluhan kesehatan yang sering di rasakan oleh pekerja yaitu dehidrasi banyak dirasakan oleh pekerja karena pekerja yang jarang mencukupi asupan cairan atau air. Begitu pula pada keluhan heat rash, keluhan ini dirasakan para pekerja yang jarang menjaga hieginitas diri. Oleh sebab itu, perlunya pengendalian iklim kerja baik dalam lingkungannya maupun pekerjanya. Pengendalian tersebut seperti Training (pendidikan/latihan), Pengendalian tekanan panas melalui penerapan hygiene.

Kata kunci: Iklim Kerja, Keluhan Kesehatan, NAB

\section{PENDAHULUAN}

Tempat kerja merupakan tempat dimana terdapat pekerja yang bekerja atau lingkungan yang biasa dimasuki oleh pekerja untuk urusan pekerjaan. Hal tersebut dapat diketahui bahwa pada tempat atau lingkungan kerja tentunya memiliki potensi bahaya yang dapat membahayakan/ memengaruhi pada kesehatan dan keselamatan pekerja. Kesehatan dan Keselamatan kerja juga merupakan hal yang wajib diterapkan pada saat bekerja ${ }^{1}$. Saat ini banyak tempat kerja menggunakan mesin produksi yang cukup canggih yang dapat menghasilkan produksi atau produk yang maksimal. Perkembangan kemajuan pada teknologi di bidang industri dapat menyebabkan dampak terhadap lingkungan kerja terutama dampak negatif. Hal tersebut dikarenakan meningkatnya jumlah hingga jenis bahaya yang ditimbulkan di tempat kerja yang dapat berakibat penyakit akibat kerja hingga kecelakaan kerja ${ }^{2}$.

Kesehatan dan Keselamatan Kerja (K3) bermakna perlindungan bagi para pekerja yang merupakan aset berharga bagi organisasi maupun perusahaan dari terjadinya penyakit akibat kerja (PAK) hingga kecelakaan kerja (KK), Pernyataan tersebut telah di atur dalam Undang-Undang Republik Indonesia No. 13 Tahun 2003 tentang Ketenagakerjaan. Peraturan tersebut diperlukannya agar menciptakan tempat kerja yang terjamin keamanannya, sehat serta nyaman pada pekerja dalam melaksanakan tugasnya lalu dapat mencegah timbul terjadinya penyakit akibat kerja hingga kecelakaan kerja ${ }^{3}$.

Iklim kerja sendiri merupakan gabungan yang berasal dari suhu udara, kelembapan, panas radiasi dan kecepatan dari aliran udara ${ }^{1}$. Iklim kerja bersuhu panas berasal dari munculnya energi panas yang kemudian dialirkan langsung maupun dengan perantara hingga energi itu masuk ke tempat kerja. Kemudian energi tersebut menjadi tekanan atau suhu panas yang memberikan beban tambahan bagi pekerja ${ }^{2}$. Kondisi tersebut dapat memperburuk kesehatan pekerja jika bekerja pada beban kerja dengan kategori berat. Pada kondisi tersebut pekerja akan membutuhkan energi yang besar jika dibandingkan pada pekerja yang bekerja di 
tempat kerja dengan suhu nyaman sekitar $24^{\circ} \mathrm{C}$ $-26^{\circ} \mathrm{C}^{1}$.

Lingkungan kerja bersuhu panas banyak permasalahan yang terjadi jika dibandingkan pada lingkungan kerja bersuhu dingin, dikarenakan manusia lebih mudah melindungi diri dari pengaruh suhu dingin dibanding panas. ACGIH sudah menetapkan tolak ukur dalam mengevaluasi iklim kerja yaitu dengan menggunakan WBGT (Wet Bulb Globe Temperature). WBGT tersebut, pada Permenakertrans Nomor 13 Tahun 2011 yang dapat disebut dengan ISBB (Indeks Suhu Basah dan Bola). Jika pekerja terpapar oleh kondisi iklim kerja dengan suhu panas yang melebihi Nilai Ambang Batas (NAB) yang diizinkan maka dapat menyebabkan timbulnya penyakit akibat kerja atau kecelakaan kerja.

Bekerja pada suhu panas dapat menimbulkan masalah kesehatan baik fisik pekerja maupun psikologis pekerja. Kondisi respon secara fisiologis yang terjadi seperti pada peningkatan denyut nadi dan suhu tubuh. Pekerja yang terpapar oleh suhu panas secara kontinyu dapat menimbulkankan terjadinya heat rash, heat cramp, heat syncope, heat exhaustion, heat stroke, malaria, dehidrasi hingga hipertermia ${ }^{1}$.

Ada beberapa kondisi yang disebabkan iklim kerja panas salah satu kondisi tersebut yaitu heat stress (tekanan panas). Heat stress merupakan total dari beban panas yang di terima oleh tubuh yang di dalamnya merupakan gabungan dari beban kerja secara fisik hingga faktor dari lingkungan seperti suhu lingkungan dan faktor pakaian yang dikenakan. Efek pada heat stress akan berdampak pada terjadinya keluhan kesehatan ${ }^{4}$, seperti dehidrasi. Dehidrasi dapat terjadi karena penguapan yang berlebihan yang dapat mengurangi volume darah, kemudian pada tahap awal pada aliran darah akan menurun hingga otak akan kekurangan asupan oksigen. Kemudian ada yang dinamakan Heat Rash, kondisi tersebut yang biasa terjadi yaitu prickly heat yang terlihat sebagai bercak merah. Hal tersebut dapat terjadi akibat adanya penyumbatan pada kelenjar keringat. Keluhan kesehatan tersebut memiliki gejala seperti lecet yang terjadi berkelanjutan pada tubuh dan rasa panas yang ditambah rasa gatal yang menyengat. Kemudian ada pula yang dinamakan Heat Exhaustion dapat disebabkan oleh kekurangan cairan tubuh atau elektrolit. Gejala yang biasanya terjadi pada kelelahan akibat panas yaitu sakit kepala, lemas, pusing, mual, muntah, diare, hingga kehilangan koordinasi ${ }^{5}$.

Penelitian yang dilakukan di Australia dengan sasaran buruh yang bekerja pada tambang bawah tanah yang terdapat pada kondisi lingkungan dengan suhu sekitar 36,2C, menunjukkan bahwa terdapat $60 \%$ buruh yang memulai bekerja akan dalam kondisi dehidrasi. Penelitian di tempat lain dilakukan pada pekerja yang bekerja diluar ruangan memperlihatkan bahwa $79 \%$ dari pekerja menderita dehidrasi ${ }^{6}$. Penelitian yang dilakukan di Indonesia pada 
pekerja di bagian boiler pada PT. Albasia Sejahtera Mandiri Semarang. Diketahui bahwa terdapat pengaruh yang cukup tinggi antara iklim kerja bersuhu panas terhadap kejadian dehidrasi dengan hasil dari nilai $p$-value sebesar 0,023 atau $p \leq 0,05$. Berdasarkan hal tersebut dapat diketahui bahwa iklim kerja panas dapat mempengaruhi kondisi pekerja seperti dehidrasi.

Sebelum adanya lampu, alat penerangan pada malam hari yaitu lilin. Lilin merupakan barang yang sangat di butuhkan dari dulu hingga sekarang. Industri lilin merupakan industri yang bergerak dalam pembuatan lilin, baik lilin biasa, lilin hias hingga lilin beraroma. Industri pembuatan lilin ini berada di kota Surabaya. Membuat lilin memerlukan beberapa proses yang salah satunya adalah pemasakan bahan dasar lilin.

Pemasakan dalam proses membuat lilin sangat dibutuhkkan dalam memasak atau melumerkan bahan baku lilin yang salah satunya yaitu parafin. Pada proses pemasakan ini pula, para pekerja selalu berhadapan dalam iklim kerja yang tidak nyaman yang dalam hal ini identik dengan iklim kerja panas karena adanya pemasakan tersebut yang menggunakan api. Iklim kerja dengan suhu ruang yang panas dapat mempengaruhi kondisi fisik dan mental pekerja. Dampak yang sering terjadi pada pekerja akibat klim kerja panas yaitu salah satunya dehidrasi, tetapi masih banyak dampak lain dari iklim kerja panas yang diterima oleh pekerja seperti reat rash. Berdasarkan latar belakang tersebut, maka penulis tertarik untuk meneliti tentang gambaran dan pengendalian iklim kerja dan keluhan kesehatan pada pekerja.

\section{METODE PENELITIAN}

Lokasi penelitian ini dilakukan pada industri lilin yang terletak di Kota Surabaya, Jawa Timur. Jenis penelitian yang digunakan adalah penelitian deskriptif dengan menggunakan rancangan cross sectional study. Populasi yang di gunakan dalam penelitian ini adalah pekerja yang bekerja di bagian produksi dan pengepakan dan finishing. Sampel dalam penelitian ini adalah seluruh pekerja yang bersedia menjadi responden dalam penelitian ini yaitu pekerja yang bekerja dibagian produksi berjumlah 21 orang dan pada bagian finishing dan pengepakan berjumlah 17 orang dengan total seluruhnya yaitu 38 orang. Sumber dari data yang akan digunakan pada penelitian ini yaitu: data primer yakni data dari hasil wawancara pada Pekerja dan data sekunder dari data pengukuran lingkungan. Hasil dari data tersebut akan disajikan dalam bentuk Tabel dan juga narasi.

\section{HASIL DAN PEMBAHASAN}

\section{Hasil Penelitian}

\section{Pengukuran Iklim Kerja}

Iklim kerja merupakan kombinasi dari suhu kerja, kecepatan udara, gerakan udara, kelembaban udara dan suhu radiasi di suatu lingkungan kerja. Pada tempat kerja yang 
memiliki iklim kerja yang tidak nyaman, tidak sesuai dengan syarat yang ditentukan dapat menurunkan kapasitas kerja yang berakibat menurunnya efisiensi dan produktifitas kerja pekerja. Suhu udara yang dianggap nyaman bagi orang Indonesia sekitar $24^{\circ} \mathrm{C}-26^{\circ} \mathrm{C}$.

Berikut ini adalah hasil pengukuran iklim kerja pada dua bagian pada indutstri pembuatan lilin.

Tabel 1.Distribusi Hasil Pengukuran Iklim Kerja

\begin{tabular}{|c|c|c|c|}
\hline \multirow[b]{2}{*}{ No. } & \multirow[b]{2}{*}{$\begin{array}{l}\text { Nama } \\
\text { lokasi }\end{array}$} & \multicolumn{2}{|c|}{ ISBB $\left({ }^{\circ} \mathrm{C}\right)$} \\
\hline & & $\begin{array}{l}\text { Bag. } \\
\text { Produksi }\end{array}$ & $\begin{array}{c}\text { Bag. } \\
\text { Finisihing/ } \\
\text { Pengepakan }\end{array}$ \\
\hline 1 & Titik 1 & 31,7 & 27,3 \\
\hline 2 & Titik 2 & 32,4 & 29,9 \\
\hline 3 & Titik 3 & 32,1 & 30,1 \\
\hline 4 & Titik 4 & 31,7 & 27,7 \\
\hline 5 & Titik 5 & 30,6 & 27,0 \\
\hline 6 & Titik 6 & 31,9 & 28,9 \\
\hline 7 & Titik 7 & 33,1 & 29,1 \\
\hline 8 & Titik 8 & 30,4 & 27,5 \\
\hline 9 & Titik 9 & 32,3 & 30,0 \\
\hline 10 & Titik 10 & 33,9 & 31,1 \\
\hline
\end{tabular}

Berdasarkan data pada Tabel 5.1, diketahui bahwa hasil pengukuran iklim kerja pada 2 bagian kerja yang dilakukan di 10 titik mendapatkan hasil sebagian besar memiliki nilai ISBB $>30^{\circ} \mathrm{C}$. Hasil ini nantinya akan di analisis berdasarkan beban kerja dari pekerja sehingga akan mendapatkan hasil kesesuaian iklim kerja pada pekerja.

\section{Gambaran Keluhan Kesehatan}

Keluhan kesehatan adalah keadaaan seseorang yang mengalami gangguan kesehatan atau kejiwaan, baik karena penyakit akut, penyakit kronis meskipun selama sebulan terakhir tidak mempunyai keluhan. Keluhan kesehatan dapat terjadi pada pekerja yang berkerja di lingkungan yang tidak nyaman seperti lingkungan bersuhu panas. Ada beberapa keluhan yang dapat terjadi pada pekerja yang bekerja di lingkungan diantaranya yaitu dehidrasi dan heat rash. Berikut ini adalah data para pekerja yang bekerja dibagian produksi berjumlah 21 orang pada bagian finishing dan pengepakan berjumlah 17 orang dengan total seluruhnya yaitu 38 orang yang memiliki keluhan tersebut.

Tabel. 2 Distribusi keluhan kesehatan pekerja

\begin{tabular}{lcccc}
\hline Keluhan & Bag. Produksi & \multicolumn{2}{c}{$\begin{array}{c}\text { Bag. } \\
\text { Finisihing/ } \\
\end{array}$} & Pengepakan \\
\cline { 2 - 5 } & Tidak & Ya & Tidak & Ya \\
\hline Dehidrasi & 6 & 15 & 7 & 10 \\
\hline Heat Rash & 9 & 12 & 6 & 9 \\
\hline
\end{tabular}

Berdasarkan Hasil pada Tabel 2, mengenai keluhan kesehatan yang diperoleh pada pekerja pada bagian produksi dari total pekerja yaitu 21 orang diketahui 15 orang sering mengalami dehidrasi dan 12 orang sering mengalami heat rash. Pada pekerja bagian finishing dan pengepakan dari total pekerja yaitu 17 orang diketahui 10 orang sering mengalami dehidrasi dan 9 orang sering mengalami heat rash.

\section{Gambaran Beban Kerja}

Pada Industri lilin merupakan industri yang bergerak dalam pembuatan lilin, baik lilin 
biasa, lilin hias hingga lilin beraroma. Industri pembuatan lilin ini berada di kota Surabaya Membuat lilin memerlukan beberapa proses yang salah satunya adalah pemasakan bahan dasar lilin.

Berdasarkan hasil pengamatan yang telah dilakukan, diketahui bahwa beban kerja pada industri pembuatan lilin yaitu beban kerja sedang. Beban kerja sedang membutuhkan kebutuhan kalori 750 - 2000 kalori dalam setiap bekerja. Hal tersebut di sesuaikan dengan pengaturan waktu kerja yaitu 75\%-100\% dengan $25 \%$ waktu istirahat dari 8 jam kerja.

\section{Pembahasan}

Iklim kerja adalah suatu kombinasi dari suhu kerja, kelembaban udara, kecepatan gerakan udara dan suhu radiasi pada suatu lingkungan kerja. Iklim kerja yang tidak nyaman, tidak sesuai dengan persyaratan lingkungan kerja dapat menurunkan efisiensi hingga produktifitas pada pekerja. Suhu udara yang dianggap nyaman bagi orang Indonesia sekitar $24^{0} \mathrm{C}-26^{\circ} \mathrm{C}$.

Faktor fisik pada tempat kerja banyak sekali memberikan pengaruh pada lingkungan sekitarnya yang dapat berdampak terhadap pekerja. Pengaruh yang dapat memengaruhi tersebut yaitu iklim kerja yang didalamnya mencakup suhu, kecepatan udara, hingga kelembaban ${ }^{2}$.

Proses dalam produksi sebagian besar menghasilkan suhu udara yang panas atau tinggi. Hal tersebut diperoleh dari sumber- sumber panas tertentu biasanya seperti mesinmesin produksi. Pada dasarnya di dalam dunia industri kita sering berjumpa dengan perbedaan suhu yang besar antara satu tempat kerja dan lainnya. Hal ini menyebabkan munculnya perbedaan suhu yang besar. Suhu panas mempunyai pengaruh pada kondisi kesehatan tubuh manusia. Satu hal yang sangat perlu di perhatikan untuk pekerja yang sedang bekerja di tempat kerja atau lingkungan yang bersuhu panas yaitu tentang adanya sumber panas ${ }^{7}$. Salah satu jenis sumber panas yang perlu diketahui oleh pekerja yaitu panas yang berasal dari mesin terutama dalam kegiatan produksi. Oleh sebab itu, semakin banyaknya mesin pada proses produksi maka akan sangat berpotensi menghasilkan suhu panas yang semakin besar.

Pengukuran Iklim kerja yang dilakukan pada industri pembuatan lilin dengan 10 titik pengukuran di dua bagian yaitu bagian produksi, bagian finishing dan pengepakan, diketahui memiliki hasil yaitu sebagian besar memiliki nilai $\mathrm{ISBB}>30^{\circ} \mathrm{C}$. Berdasarkan pengamatan yang telah dilakukan beban kerja pada industri pembuatan lilin yaitu beban kerja sedang. Beban kerja sedang membutuhkan kalori 750-2000 kalori dalam setiap bekerja. Hal tersebut di sesuaikan dengan pengaturan waktu kerja yaitu 75\%-100\% dengan 25\% waktu istirahat dari 8 jam kerja. Pengaturan beban kerja ini di disesuaikan pada tingkat kegiatan dan kalori yang dihasilkan. Beban kerja sedang memiliki jenis pekerjaan seperti berdiri, mengangkat 
hingga mendorong dengan kebutuhan kalori 750-2000 kalori ${ }^{1}$.

Hasil analisis pada bagian produksi, diketahui 10 titik pengukuran memiliki hasil pengukuran seluruhnya $>30^{\circ} \mathrm{C}$ dengan waktu kerja $75 \%-100 \%$ dengan $25 \%$ waktu istirahat (waktu kerja 6-7 jam dengan waktu istirahat 1-2 jam). Jika dibandingkan dengan standar ISBB nilai tersebut berada di atas nilai ambang batas karena nilai ambang batas untuk beban kerja sedang dengan waktu kerja 75\%-100\% adalah $28^{\circ} \mathrm{C}$. Analisis iklim pada bagian industri dapat di simpulkan yaitu hasil tersebut melebihi ambang batas yang telah di tentukan.

Hasil analisis lingkungan kerja memperoleh hasil hampir sama pada bagian finishing dan pengepakan. Hasil analisis pada bagian finising dan pengepakan dengan 10 titik pengukuran memiliki hasil pengukuran yaitu 6 titik $>30{ }^{\circ} \mathrm{C}$ dan 4 titik berkisar di $29{ }^{\circ} \mathrm{C}$. Tingkat indeks suhu bola basah pada dua bagian kerja yang di ukur dalam masing-masing 10 titik, di ketahui tidak satupun hasil memiliki nilai $28^{\circ} \mathrm{C}$. Nilai ambang batas dalam iklim kerja yaitu $28^{\circ} \mathrm{C}$. Hasil rata-rata ISBB dari dua bagian kerja pada industri lilin tersebut yaitu bagian produksi rata-rata ISBB $32^{\circ} \mathrm{C}$, sedangkan bagian finishing dan pengepakan memiliki rata-rata ISBB $30,4^{\circ} \mathrm{C}$. Hal ini menunjukan bahwa berdasarkan hasil rata-rata 10 titik dari ke dua bagian kerja tersebut memiliki nilai ISBB hasil pengukuran lebih besar dari nilai NAB yang telah di tetapkan. Analisis iklim pada ke dua bagian kerja di industri lilin dapat di simpulkan bahwa hasil tersebut melebihi ambang batas yang telah di tentukan.

Bekerja di iklim kerja panas juga memiliki beberapa dampak pada kesehatan atau keluhan kesehatan. Pada industri ini lingkungan para pekerja lebih dominan iklim kerja panas, memiliki risiko kesehatan yaitu seperti dehidrasi dan gangguan seperti heat rash. Hasil yang diperoleh dalam penelitian ini, mengenai keluhan kesehatan diperoleh pada pekerja pada bagian produksi dari total pekerja yaitu 21 orang diketahui 15 orang sering mengalami dehidrasi dan 12 orang sering mengalami heat rash. Pada pekerja bagian finishing dan pengepakan dari total pekerja yaitu 17 orang diketahui 10 orang sering mengalami dehidrasi dan 9 orang sering mengalami heat rash.

Keluhan tersebut sering di rasakan oleh pekerja yang banyak bekerja di iklim kerja panas. Keluhan dehidrasi banyak dirasakan oleh pekerja karena pekerja yang jarang mencukupi asupan cairan atau air. Para pekerja jarang minum, mereka akan minum kebanyakan pada saat istirahat, karena mereka ingin fokus bekerja. Begitu pula pada keluhan heat rash, keluhan ini dirasakan para pekerja yang jarang menjaga hieginitas diri. Lingkungan panas sangat berpotensi menghasilkan keringan berlebih pada tubuh. Bagian pekerja yang jarang membersihkan diri akan menimbulkan gangguan pada kulitnya seperti gatal, ruangruang dan biang keringat. 


\section{Pengendalian Iklim Kerja Panas}

Pengendalian dampak dari iklim kerja panas yaitu dipusatkan disekitar penyebabnya. Cara pengendalian yang biasa digunakan adalah pengedalian secara umum dan pengendalian secara khusus. Pengendalian secara umum, biasanya terdiri dari Training (pendidikan/ latihan) sebagai contoh Pelatihan atau pendidikan bagi calon atau pekerja sebelum ditempatkan di tempat kerja. Pengendalian tekanan panas atau suhu panas dengan penerapan hygiene. Cara tersebut dilakukan oleh seseorang seperti pekerja dalam mengurangi risiko timbulnya penyakit yang diakibatkan oleh suhu panas. Beberapa cara lainnya melalui penerapan hygiene sanitasi seperti Aklimatisasi, Self determination, pengandalian cairan, perilaku diet sehat, melakukan gaya hidup sehat (rajin berolahraga) hingga pada pakaian kerja.

Pengendalian secara khusus yang dapat dilakukan dalam mengendalikan iklim kerja yang tidak sesuai dengan pengendalian secara teknis seperti mengurangi beban kerja yang dikerjakan, menurunkan suhu udara di lingkungan kerja, menurunkan kelembaban pada udara hingga menurunkan panas. Kemudian ada pengendalian secara administratif yaitu dengan melakukan perubahan pada proses kerja yang dilakukan agar dapat membatasi terjadinya risiko paparan dari suhu panas. Selanjutnya yaitu perlindungan perorangan dengan dilaksanakan secara perorangan (setiap tenaga kerja). Pada suhu kerja panas, perlindungan pada seorang pekerja seperti berupa pakaian pendingin yang di gunakan, dapat juga pakaian yang dapat memantulkan panas yang tinggi.

\section{SIMPULAN DAN SARAN}

\section{Simpulan}

Tingkat indeks suhu bola basah pada dua bagian kerja yang di ukur dalam masing-masing 10 titik, di ketahui tidak satupun hasil memiliki nilai $28^{\circ} \mathrm{C}$. Nilai ambang batas dalam iklim kerja yaitu $28^{\circ} \mathrm{C}$. Hasil rata-rata ISBB dari dua bagian kerja pada industri lilin tersebut yaitu bagian produksi rata-rata ISBB $32^{\circ} \mathrm{C}$, sedangkan bagian finishing dan pengepakan memiliki rata-rata ISBB $30,4^{\circ} \mathrm{C}$. Hal ini menunjukan bahwa berdasarkan hasil rata-rata 10 titik dari ke dua bagian kerja tersebut memiliki nilai ISBB hasil pengukuran lebih besar dari nilai NAB yang telah di tetapkan. Analisis iklim pada ke dua bagian kerja di industri lilin dapat di simpulkan bahwa hasil tersebut melebihi ambang batas yang telah di tentukan.

Keluhan tersebut sering di rasakan oleh pekerja yang banyak bekerja di iklim kerja panas. Keluhan dehidrasi banyak dirasakan oleh pekerja karena pekerja yang jarang mencukupi asupan cairan atau air. Begitu pula pada keluhan heat rash, keluhan ini dirasakan para pekerja yang jarang menjaga hieginitas diri. Diketahui keluhan kesehatan yang diperoleh pada pekerja bagian produksi dari total pekerja yaitu 21 orang diketahui 15 orang sering mengalami dehidrasi 
dan 12 orang sering mengalami heat rash. Pada pekerja bagian finishing dan pengepakan dari total pekerja yaitu 17 orang diketahui 10 orang sering mengalami dehidrasi dan 9 orang sering mengalami heat rash.

\section{Saran}

Perlunya pengendalian iklim kerja baik dalam lingkungannya maupun pekerjanya. Pengendalian tersebut yaitu pengendalian secara umum seperti Training (pendidikan/latihan), pengendalian tekanan panas melalui penerapan hygiene. Hingga Pengendalian secara khusus yaitu mengurangi beban kerja, menurunkan suhu udara, menurunkan kelembaban udara, menurunkan panas radiasi, pengendalian secara administratif, perlindungan perorangan. Kemudian perlunya menjaga hieginitas atau kebersihan diri sendiri agar kondisi fisik di dalam ataupun di luar tubuh tetap dalam kondisi sehat.

Rekomendasi dalam perbaikan masalah iklim kerja yang kurang sesuai yaitu sangat memerlukan tindakan tegas dari pihak manajemen untuk dapat menyesuaian kondisi fisik lingkungan kerja. Bagian K3 (HSE) tetap terus memberikan pengarahan kepada pekerja tentang kenyamanan dalam bekerja dan ketentuan waktu yang sesuai untuk pekerja dalam melakukan suatu pekerjaan dengan disesuaikannya iklim kerja dan lamanya dalam bekerja. Perlunya peningkatan dalam pengawasan pada pekerja saat melakukan pekerjaan terutama pada pekerjaan yang memiliki bahaya atau berisiko tinggi dalam menyebabkan kecelakaan.

Perlunya peningkatkan pada sumber daya manusia seperti staff K3 (HSE) / pengawas dalam penerapan $\mathrm{K} 3$ di perusahaan terutama pada penyehatan di lingkungan kerja. Pada setiap tempat kerja perlu dilakukan controlling untuk mencegah adanya hasil pengukuran iklim kerja yang melebihi NAB. Hal lain yang juga diperlukan yaitu adanya rotasi kerja atau shift kerja, pemberian asupan gizi yang sesuai dengan aktivitas pekerja hingga adanya ventilasi di dalam ruang kerja agar pertukaran udara tersebut maksimal.

\section{REFERENSI}

1. Suma'mur. Higene Perusahaan dan Kesehatan Kerja (HIPERKES) (2nd ed.). Jakarta: CVSagung Seto. 2014.

2. Suma'mur. Higiene Perusahaan dan Kesehatan Kerja (HIPERKES). Jakarta: Sagung Seto. 2009.

3. Tarwaka. Keselamatan dan Kesehatan Kerja. Surakarta: Harapan Press. 2009.

4. Puspita, AD. Iklim Kerja dan Beban Kerja Terhadap Tingkat Dehidrasi Pekerja Shift Pagi bagian Injection Moulding 1 PT.X. (Research). 2015.

5. Ridley, J. Kesehatan dan Keselamatan Kerja. Jakarta: Erlangga. 2008.

6. Hughes., P dan Ferret., E. Introduction to Health and Safety at Work. Elsevier, Slovenia. 2009.

7. Soeripto, M. Higiene Industri. Jakarta: Balai FK Universitas Indonesia. 2008.

8. Dainur. Ilmu Kesehatan Masyarakat "Materi-Materi Pokok". Jakarta: Penerbit 
Widya Medika. 2012.

9. Government of Alberta (GOA). Workplace Health and Safety. 2011. http://work.alberta.ca/documents/WHSPUB-SH013.pdf

10. Kementrian Ketenagakerjaan. Peraturan Menteri Ketenagakerjaan Nomor 5 Tahun 2018. 2018. https://jdih.kemnaker.go.id/ data_puu/Permen_5_2018.pdf

11. Nur Aedi. Bahan Belajar Mandiri Metode Penelitian Pendidikan Pengolahan Dan Analisis Data Hasil Penelitian. Pengolahan Dan Analisis Data Hasil Penelitian, 2010. $1-30$.

12. Reason. Managing the Risk of Organizational Accidents. Ashgade: Publishing Ltd. Aldershot Hants. 2007.

13. Peraturan Menteri Tenaga Kerja dan Transmigrasi No. 15 PER/MEN/VIII/2008

14. Trikasjono, T. Petunjuk Praktikum K3. Yogyakarta: STTN-Batam. 2015. 